\title{
Modern Techniques for the Mapping and the Delimitation of some Protected Areas in Timis County
}

\author{
Cosmin - Alin POPESCU ${ }^{*}$, Adrian SMULEAC ${ }^{1}$, George POPESCU ${ }^{1}$ \\ ${ }^{1}$ Banat's University of Agricultural Sciences and Veterinary Medicine, Faculty of Agricultural Sciences, \\ Timisoara, Aradului Street, no. 119, R0 300645, Romania \\ *)Corresponding author, e-mail: gabi_cosmi@yahoo.com
}

BulletinUASVM Horticulture 73(2) / 2016

Print ISSN 1843-5254, Electronic ISSN 1843-5394

DOI:10.15835/buasvmcn-hort:12186

\begin{abstract}
The vegetation accounts for the biomass produced by the surface soil layer made up of inorganic elements and exposure to the Sun. The overexploitation of natural resources by heavy industry, excessive agriculture and urban development represent the most important way of biodiversity degradation, leading to the extinction of a large numbers of species. The natural vegetation plays a decisive role in the conservation of plant diversity, of animals and of the biocenosis and of the ecosystems. The goal of the study was the mapping and the delimitation of some protected areas in Timis county, areas of national interest that correspond to the IVth IUCN category (International Union for Conservation of Nature). The measurements taken in the field have been carried out by means of GNSS technology through RTK method, being the most suited by point of view of precision and fastness for recording all the details. The drawing up of the vegetation maps, or of another type, knowing the eco-systemic life layer of the whole living environment which is necessary. The following steps were taken into consideration for the project: field recognition, filed measurement, office works. The methods used in the mapping process are modern methods, and allowed the delimitation of the studied areas and their transposition in a compatible format, used in many sectors of activity: CAD or GIS.
\end{abstract}

Keywords: elevation, geo-referencing, maps, natural area, nomenclature

\section{INTRODUCTION}

Out of necessity to protect habitats and species resulting in a variety of protected areas, which differ mainly depending on the degree of protection and depending on the purpose of protection. Areas were set up so that protect the natural areas of the world in which human intervention is present, as in case of modified landscapes that have a special importance and cultural landscape. The supreme body, which has proposed to resolve this predicament, was IUCN The World Conservation Union.

The objectives taken into consideration in the study are the natural protected areas of Timis county, as follows: Meadow Pogănişului, Stachinez Marshes, Murani Swamps.

Mapping these protected natural areas help streamline and participatory conservation management, able to protect the existence of ornithological profiles, profiles botanical, today endangered, on the way for extinction. Cartographic applications in the field of protected areas can be represented by a variety of characteristic elements, taking into account the issues that need to be highlighted and valued.

This paper intends to demonstrate the practical use of a model with spatial analysis mapping in conjunction with the database created in the field 


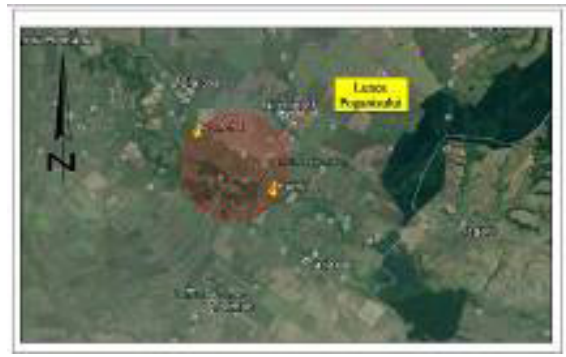

Fig.1. Objective Localization - Lunca Poganisului

of monitoring protected areas by exemplifying the utility of information technology today to highlight the landform and micro-landforms depending on environmental factors, namely: altitude, slope, expozition etc. (Caluseru et al., 2013; Horablaga et al.,2009-2010)

\section{MATERIALS AND METHODS}

Among the 14 protected areas in the county of Timis that are recognized by law, they are found in protected areas taken situated: Meadow Pogănișului, Stachinez Marshes, Swamps Murani.

Meadow Pogănișului - protected area created to protect motley tulip (Fritillaria meleagris L), plant natural monument of nature, protected by the Decree \# 237/1950, by the corresponding IUCN IV category (nature reserve of botanical type) located in Timis county, the administrative territory of Sacosu Turcesc and Tormac. The natural area has an area of 75.50 hectares and is located in the central basin of the Timis county Pogănișului valley, near the county road (DJ592A) linking the town Tormac to Stamora Romanian village (Fig.1).

The protected natural area it characterized from the point of view of achieving a management plan and land demarcation of buffer zones, the fact that it has no rural settlement in the immediate vicinity to disturb the natural balance strong.

Swamps Stachinez - is a ornithological nature reserve, including wetlands downstream of the town Stachinez, Timis County. Access to the region is provided by the upgraded existing roads and railroads Timisoara - Sannicolau Mare (Fig.2).

Currently the reserve has an area of 1194 ha, and its structure is as follows: 122 ha - Reserve itself; 1072 ha - buffer mosaic comprising: Stachinez Accumulation. Barateaz Balta; Balta Mare, Animal Husbandry and Balta Balta Verbuncu.
Swamps Murani - protected area of national interest which corresponds to category IV IUCN (nature reserve) type ornithological, located in Timis county, the administrative territory of Pischia. Natural area has a surface of 200 hectares, being in the west end of Timis County, on the eastern edge of the village Murani, lanfga county road (Dj693) linking the Seceani Pischia town, close to the A1 motorway. Bucharest - Nadlac and represents an area body of water, marshes, reed, reeds, lawns and bushes (Fig.3). The protected area has several types of habitats consisting of rivers and backwaters, marshes, forests transition habitats, crops and pastures Pannonian with a wide variety of flora and fauna of the wetlands.

Vegetation maps and plans are documents useful to estimate crop diversity within communities, but also for environmental impact assessment, management of protected areas and habitat classification. The making of vegetation maps is not strictly descriptive but the biogeography science itself being the result of complex analysis of interdeterminations between ecological factors. The surfaces of smaller size, topographic maps of the territory correspond exactly to the investigated ones and show the natural limits (shoreline, watershed, and other details planimetric landforms etc.).

The study purpose of terrestrial measurements in the context of protected areas is to collect data in the field using the most appropriate method, to process this data using computers and applications that specialize and obtain a digital terrain model (DTM).

GPS technology has been used because of advantages compared to other methods:

- The land is open, providing good visibility to the satellite network.

- In the earlier stages of preparation work we have identified a point known network state 


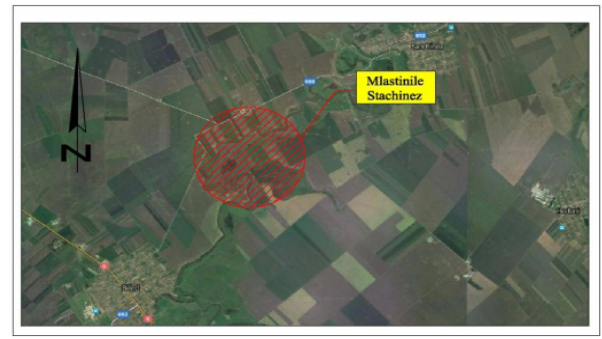

Fig.2. Objective Localization - Mlastinile Stachinez

that provides optimal conditions for using this technology.

- High speed with which it can make data acquisition (compared to the method terrain, respectively with total station)

- The size of the project does not justify the use of photogrammetry and LIDAR method.

GPS is a global positioning system, i.e. a system thanks to which, starting from mobile positions along the orbits of satellites can be determined using the position of the points located in any part of the Earth. The reference should therefore be geocentric, unique globe and fixed on the Earth's movement. GPS system is adopted for the system as WGS'84 (World Geodetic System 1984).

A GPS 1200 was used with the following characteristics:

- Receiver GRX 1200 - to calculate data of satellites;

- Antenna - the user interface used with the keyboard or using the touch screen;

- Leica Geo Office - Office program including a range of applications GPS for 1200;

- Leica Geo Office - program reference stations;

GRX 1200-12 and 12-channel L1 L2 channels, code and phase, real-time reference stations.

Data processing takes place after the acquisition of data from the field using the corresponding technique of data acquisition and downloading of the data from the instrument ( or data support the internal memory or data card, etc. ).

The format of the data files obtained is defined or selected by the operator. Thus, as required, the operator can use predefined formats (native) from machine manufacturer that makes them available or can define new formats tailored to their needs.

It is important to note that the manufacturer can protect native data formats and data process-

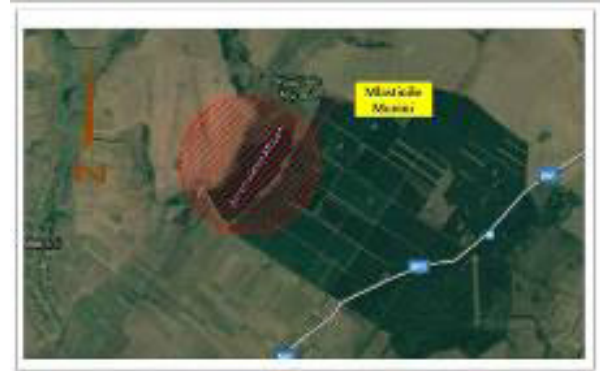

Fig.3. Objective Localization - Mlastinile Murani

ing will be difficult if we do not have programs that "understand" these formats run with thus, we cannot process the data or do with difficulty, being forced to use software conversion data. Sometimes these programs lose data at the time of conversion, which may adversely affect the desired result.

Data Compatibility with programs for their processing is an essential element in the decision to purchase / use of equipment and processing programs.

Through data obtained from measurements and sought a digital terrain measurement model (DTM). This digital model can be use later for multiple purposes:

- Obtaining leveling curves;

- Obtaining longitudinal and transversal profiles;

= Obtaining necessary topographical plans for designer.

Currently there are varieties of computer programs used for data processing of measurement results. Many of these programs originate from software packages developed from the direction of CAD (Computer Aided Design). (Bostan et al., 2009-2010, Samfira et al., 2013)

\section{RESULTS AND DISCUSSION}

The result of this study highlights directly the areas that have been referred to starting from the reminiscence of the old moors that covered till the middle of the VIII th century all these lands, from clusters to trees, as well as the vegetal covers, developing in tight interdependence, and being constituted in this respect the permanent base of the vegetation maps, also demonstrating the ability of GNSS technology, digital cartographic representations made implicitly, to centralize and to use a complex database that contains information very different (parametric and nonparametric). 


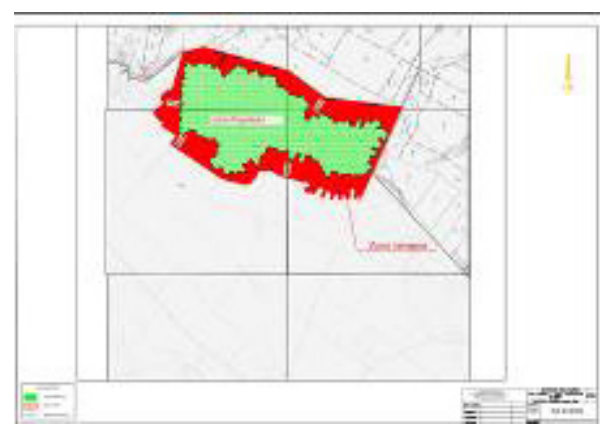

Fig. 4. Zone framing plan

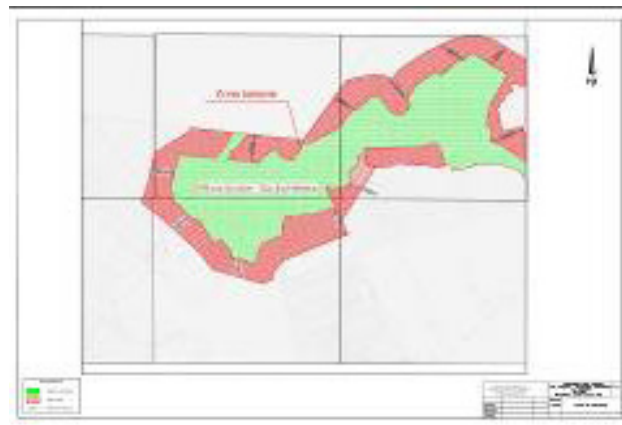

Fig.6. Zone framing plan

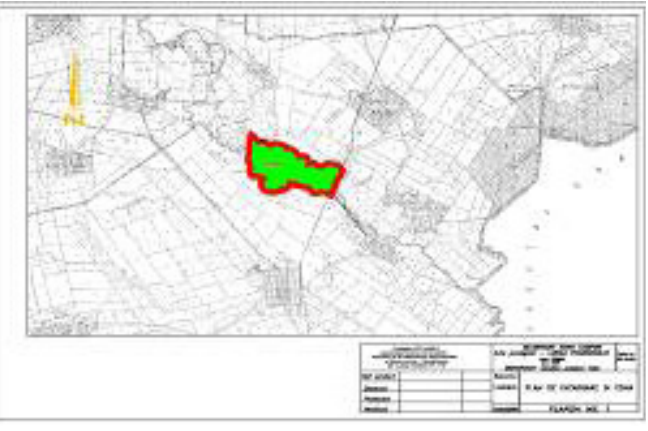

Fig. 5. Buffer zone delimitation

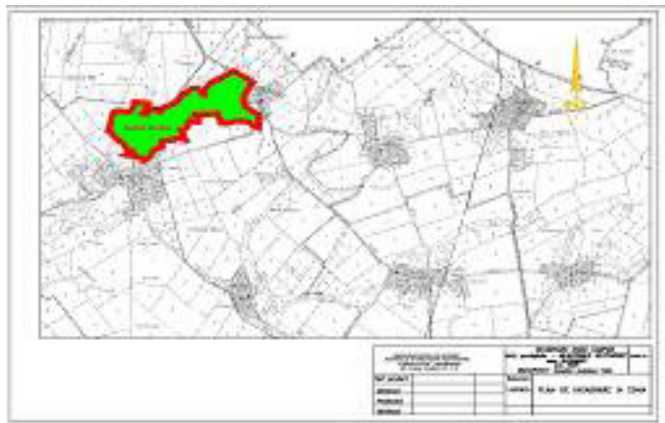

Fig.7. Buffer zone delimitation

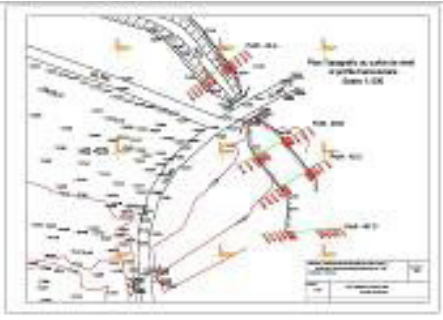

Fig.8.

Transversal profile

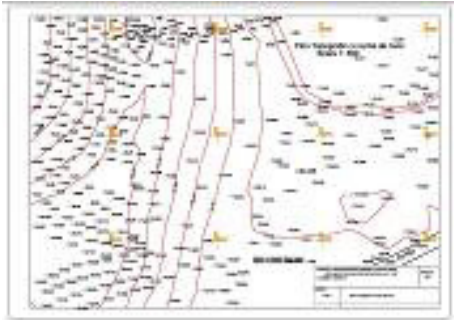

Fig.9.

Topographical plan with levelling curves

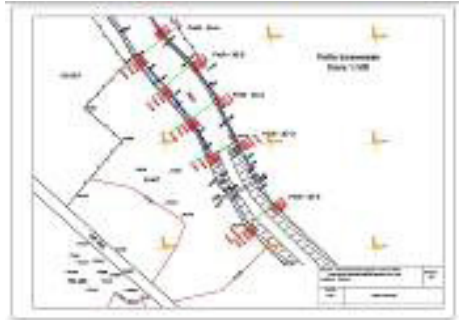

Fig.10.

Topographical plan with levelling curves and profiles
An important advantage of this technology is that information can be updated and permanently developed.

In this way the technology can be useful for entities implicated in protected area management: local administrations, protected area administrators, research institutions, the ministry of agriculture, the ministry of environment, APIA, etc.; interested in conservation, management, exploitation and subvention of protected zones.

Lunca Poganisului - demarcation of the buffer zone went from the arguments above regarding anthropogenic influence on the development of natural protected area,in accordance scientific premises of development of protected natural ecosystems. To do this, the width of the buffer zone all around the protected area was established taking into account natural boundaries that can generate dynamic changes in natural protected area (Fig.4, Fig.5).

Southern area - West Meadow Pogănişului protected area, identified by PdT737 from which the stability was a buffer zone $746.75 \mathrm{~m}$.

Mlastinile Stachinez - The region where the Satchinez village is located, cadastral territory is a plain stretched with slight ondulations resulting from alluvial deposits irregulary made from 


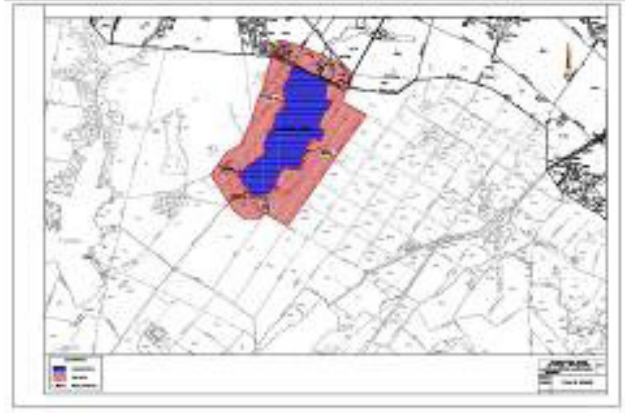

Fig.11. Zonal framing plan

floodwaters (Fig.6, Fig.8, Fig.9, Fig.10). The buffer zone is important both for the protection of the reserve and the fact that is feeding place for many birds (Fig.7).

This includes marshes and ponds permanent and temporary lake Stachinez surfaces occupied by reeds, and farmland.

Mlastinile Murani - In the buffer zone of the protected area (which is the only body of water) were included all type formations shrubbery and bushes or trees that are close to the water surface (Fig.11). They were included in the buffer zone on the north side PDT (embankments or maracinisuri) as nesting places (Fig.12).

To have delimitated units and apply a uniform management in the buffer zone all agricultural parcels bordering the lake were included, as follows: A38, A44 up to the summit of the hill as buffer zone.

\section{CONCLUSION}

The maps regard the protected areas, Lunca Poganisului, the Moors from Murani, the Moors Satchinez, which is the object of this paper as well as other areas on the territory of Romania that played an important role in terms of knowing one of the important components of our life environment - vegetation, valuable economic sources that preserved the environment conditions and biodiversity. The practical usability of those maps can be proven permanently, in different areas such as forestry, grassland farming, the ecological setup of the territory or formation of the network of reservations Natura 2000.

There are many possible solutions, as we have shown, but proper preparation work has the effect of reducing costs and providing expected results in the shortest time.

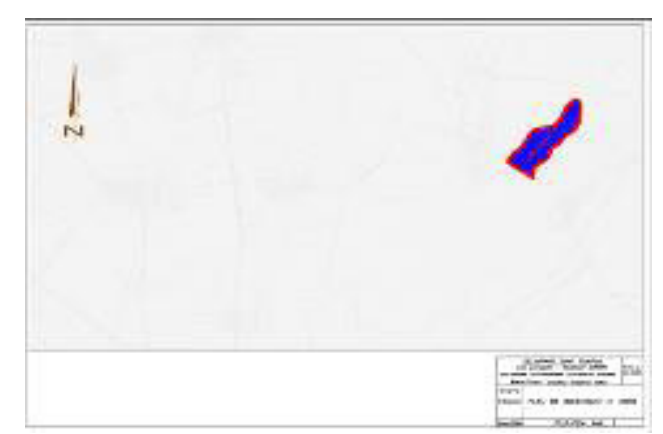

Fig.12. Buffer zone Delimitation

Unfortunately, in the last 20-30 years it has not succeeded in preserving and maintaining geodetic and leveling networks and is difficult to find useful and timely information to perform quality work.

The emergence of new methods of measurements (eg RTK-ROMPOS) failed to boost the quality of data collection activity because the national network of fixed stations is far from being achieved and do not provide the accuracy required for such work.

The need for education institutions to focus more on both the theoretical and the practical on procurement data (measurements) and their computer processing is felt.

Real-life projects realized with certainty that transpires surveyor role is increasingly important in all aspects of planning and execution of all projects materialize on the ground.

That means the responsibility of the surveyor increases, hence the need for the users to be educated, know the best equipment and to master the best methods of data processing, so that the beneficiary is be able to achieve the intended purpose.

\section{REFERENCES}

1. Alina Lavinia Caluseru, Luminita Cojocariu, NM Horablaga, Despina-Maria Bordean, Adina Horablaga, A. Cojocariu, Aurica Breica Borozan, T. Iancu, „Romanian National Strategy for the Conservation of Biodiversity 2013-2020-Integration of European Environmental policies", Albena, Bulgaria, Section Environmental Legislation, multilateral, relations and funding opportunities, factor de impact 3. 1314-2704, vol. II, 1622 iunie, 2013, p. 723-728.

2. Adina Horablaga, Nicolae Marinel Horablaga, Osman Andrei, Banatean-Dunea Ioan- The impact of economic activities within the naturalprotected areas in the West Region, 2014 May, Banat's University of Agricultural Sciences and Veterinary Medicine from Timisoara "King Mihai I of Romania" vol 46, Research Journal of Agricultural 
Science, ISSN 2066-1843, CABI (since 2009 - at section Plant Sciences, page 14), ULRICH'S PERIODICALS DIRECTORY (since 2010), Index Copernicus International (since 2009).

3. C. Bostan, F. Borlea, Alma Nicolin, I. Banatean Dunea, Adina Horablaga, I. Samfira- Minimum conservation measures for Lunca Poganisului protected area, Research Journal of Agricultural Sciences, vol. 45 nr. 2, 2013, ISSN 2066-1843, CABI (since 2009 - at section Plant Sciences, page 14),
ULRICH'S PERIODICALS DIRECTORY (since 2010), Index Copernicus International (since 2009).

4. Samfira Ionel, M-Kiss Andrei, Popescu Alin-Cosmin, Craciunescu Adam, Dragomir Lucian, Barliba Costel - Studii de conservare descriptiva a unor arii natural protejate din jutdeul Timis, Timisoara 2013 